\title{
Duration of preclinical, prodromal, and dementia stages of Alzheimer's disease in relation to age, sex, and APOE genotype
}

Citation for published version (APA):

Vermunt, L., Sikkes, S. A. M., van den Hout, A., Handels, R., Bos, I., van der Flier, W. M., Kern, S., Ousset, P-J., Maruff, P., Skoog, I., Verhey, F. R. J., Freund-Levi, Y., Tsolaki, M., Wallin, A. K., Rikkert, M. O., Soininen, H., Spiru, L., Zetterberg, H., Blennow, K., ... DSA Study Group (2019). Duration of preclinical, prodromal, and dementia stages of Alzheimer's disease in relation to age, sex, and APOE genotype. Alzheimer's \& Dementia, 15(7), 888-898. https://doi.org/10.1016/j.jalz.2019.04.001

Document status and date:

Published: 01/07/2019

DOI:

10.1016/j.jalz.2019.04.001

Document Version:

Publisher's PDF, also known as Version of record

\section{Document license:}

Taverne

Please check the document version of this publication:

- A submitted manuscript is the version of the article upon submission and before peer-review. There can be important differences between the submitted version and the official published version of record.

People interested in the research are advised to contact the author for the final version of the publication, or visit the DOI to the publisher's website.

- The final author version and the galley proof are versions of the publication after peer review.

- The final published version features the final layout of the paper including the volume, issue and page numbers.

Link to publication

\footnotetext{
General rights rights.

- You may freely distribute the URL identifying the publication in the public portal. please follow below link for the End User Agreement:

www.umlib.nl/taverne-license

Take down policy

If you believe that this document breaches copyright please contact us at:

repository@maastrichtuniversity.nl

providing details and we will investigate your claim.
}

Copyright and moral rights for the publications made accessible in the public portal are retained by the authors and/or other copyright owners and it is a condition of accessing publications that users recognise and abide by the legal requirements associated with these

- Users may download and print one copy of any publication from the public portal for the purpose of private study or research.

- You may not further distribute the material or use it for any profit-making activity or commercial gain

If the publication is distributed under the terms of Article $25 \mathrm{fa}$ of the Dutch Copyright Act, indicated by the "Taverne" license above, 


\title{
Duration of preclinical, prodromal, and dementia stages of Alzheimer's disease in relation to age, sex, and $A P O E$ genotype
}

\author{
Lisa Vermunt ${ }^{\mathrm{a}, *}$, Sietske A. M. Sikkes ${ }^{\mathrm{a}, \mathrm{b}}$, Ardo van den Hout ${ }^{\mathrm{c}}$, Ron Handels ${ }^{\mathrm{d}}$, Isabelle Bos ${ }^{\mathrm{d}}$, \\ Wiesje M. van der Flier ${ }^{\mathrm{a}, \mathrm{e}}$, Silke Kern ${ }^{\mathrm{f}}$, Pierre-Jean Ousset ${ }^{\mathrm{g}}$, Paul Maruff ${ }^{\mathrm{h}}$, Ingmar Skoog ${ }^{\mathrm{f}}$, \\ Frans R. J. Verhey ${ }^{\mathrm{d}}$, Yvonne Freund-Levi ${ }^{\mathrm{i}, \mathrm{j}, \mathrm{k}}$, Magda Tsolaki ${ }^{1},{ }^{\circ}$ sa K. Wallin ${ }^{\mathrm{m}}$, \\ Marcel Olde Rikkert ${ }^{\mathrm{n}}$, Hilkka Soininen ${ }^{\mathrm{o}}$, Luisa Spiru ${ }^{\mathrm{p}, \mathrm{q}}$, Henrik Zetterberg ${ }^{\mathrm{r}, \mathrm{s}, \mathrm{t}, \mathrm{u}}$, Kaj Blennow ${ }^{\mathrm{r}, \mathrm{s}}$, \\ Philip Scheltens ${ }^{\mathrm{a}}$, Graciela Muniz-Terrera ${ }^{\mathrm{v}}$, Pieter Jelle Visser ${ }^{\mathrm{a}, \mathrm{d}}$, for the Alzheimer Disease \\ Neuroimaging Initiative ${ }^{1}$, AIBL Research Group ${ }^{2}$, ICTUS/DSA study groups ${ }^{3}$ \\ ${ }^{a}$ Department of Neurology, Alzheimer Center Amsterdam, Amsterdam Neuroscience, Amsterdam UMC, Vrije Universiteit Amsterdam, Amsterdam, \\ The Netherlands \\ ${ }^{b}$ Department of Neurology, Massachusetts General Hospital, Harvard Medical School, Boston, MA, USA \\ ${ }^{c}$ Department of Statistical Science, University College London, London, UK \\ ${ }^{d}$ Department of Psychiatry and Neuropsychology, School for Mental Health and Neuroscience (MHeNS), Alzheimer Centrum Limburg, Maastricht University, \\ Maastricht, The Netherlands \\ ${ }^{e}$ Department of Epidemiology and Biostatistics, Amsterdam UMC, Vrije Universiteit Amsterdam, Amsterdam, The Netherlands \\ ${ }^{f}$ Department of Psychiatry and Neurochemistry, Neuropsychiatric Epidemiology Unit, Institute of Neuroscience and Physiology, Sahlgrenska Academy \\ at the University of Gothenburg, Gothenburg, Sweden \\ ${ }^{g}$ CHU Toulouse, Gérontopôle and INSERM UMR 1027, Toulouse, France \\ ${ }^{h}$ Cogstate Ltd, Florey Institute, University of Melbourne, Melbourne, Australia \\ ${ }^{i}$ Department of Neurobiology, Caring Sciences and Society (NVS), Karolinska University Hospital Huddinge, Stockholm, Sweden \\ ${ }^{j}$ Department of Old Age Psychiatry, Psychology and Neuroscience, King's College London, London, UK \\ ${ }^{k}$ School of Medical Sciences, Orebro University Campus USÖ, Örebro, Sweden \\ '3rd Department of Neurology, Aristotle University of Thessaloniki, Memory and Dementia Center, "G Papanicolau” General Hospital, Thessaloniki, Greece \\ ${ }^{m}$ Department of Clinical Sciences, Clinical Memory Research Unit, Lund University, Malmö, Sweden \\ ${ }^{n}$ Department of Geriatric Medicine, Radboudumc Alzheimer Centre, Radboud University Medical Center, Nijmegen, The Netherlands \\ ${ }^{o}$ Institute of Clinical Medicine, Neurology, University of Eastern Finland, Kuopio, Finland \\ p “Carol Davila” University of Medicine and Pharmacy, Geriatrics-Gerontology and Old Age Psychiatry Clinical Department - “Elias” University Clinical \\ Hospital, Bucarest, Romenia \\ q "Ana Aslan" International Academy of Aging - The Memory Clinic and Longevity Medicine, Bucarest, Romenia \\ ${ }^{r}$ Department of Psychiatry and Neurochemistry, Institute of Neuroscience and Physiology, The Sahlgrenska Academy at the University of Gothenburg, Mölndal, \\ Sweden \\ ${ }^{s}$ Clinical Neurochemistry Laboratory, Sahlgrenska University Hospital, Mölndal, Sweden \\ ${ }^{t}$ Department of Neurodegenerative Disease, UCL Institute of Neurology, Queen Square, London, UK \\ ${ }^{u} U K$ Dementia Research Institute at UCL, London, UK \\ ${ }^{v}$ Centre for Dementia Prevention, University of Edinburgh, Edinburgh, UK
}

\begin{abstract} type, and cerebrospinal fluid tau on disease duration.

\footnotetext{
${ }^{1}$ Data used in preparation of this article were obtained from the Alzheimer's Disease Neuroimaging Initiative (ADNI) database (adni.loni.us c.edu). As such, the investigators within the ADNI contributed to the design and implementation of ADNI and/or provided data but did not participate in analysis or writing of this report. A complete listing of ADNI investigators can be found at http://adni.loni.usc.edu/wp,content/uploads/how_to_apply/ ADNI_Acknowledgement_List.pdf
}

Introduction: We estimated the age-specific duration of the preclinical, prodromal, and dementia stages of Alzheimer's disease (AD) and the influence of sex, setting, apolipoprotein E (APOE) geno-

\footnotetext{
${ }^{2}$ https://aibl.csiro.au/about/aibl-research-team

${ }^{3}$ See acknowledgments.

*Corresponding author. Tel.: +31 20444 8523; Fax: +31 204448529.

E-mail address: 1.vermunt@vumc.nl
} 
Methods: We performed multistate modeling in a combined sample of 6 cohorts $(n=3268)$ with death as the end stage and estimated the preclinical, prodromal, and dementia stage duration.

Results: The overall AD duration varied between 24 years (age 60) and 15 years (age 80). For individuals presenting with preclinical $\mathrm{AD}$, age 70, the estimated preclinical $\mathrm{AD}$ duration was 10 years, prodromal AD 4 years, and dementia 6 years. Male sex, clinical setting, APOE $\varepsilon 4$ allele carriership, and abnormal cerebrospinal fluid tau were associated with a shorter duration, and these effects depended on disease stage.

Discussion: Estimates of $\mathrm{AD}$ disease duration become more accurate if age, sex, setting, APOE, and cerebrospinal fluid tau are taken into account. This will be relevant for clinical practice and trial design.

(C) 2019 the Alzheimer's Association. Published by Elsevier Inc. All rights reserved.

\section{Introduction}

Alzheimer's disease (AD) is highly prevalent and a major cause of dementia and death in elderly individuals [1-3]. Accumulation of amyloid in the brain is believed to be the first sign of the disease and can precede a clinical diagnosis of dementia by up to 20 years $[1,4,5]$. Based on the degree of cognitive impairment, $\mathrm{AD}$ is often divided into three stages: the preclinical stage, characterized by normal cognitive ability, the prodromal stage, characterized by mild cognitive impairment, and the dementia stage, with functional impairment [6-9]; however, it is unclear how long individuals with amyloid pathology spend in each stage. A better understanding of the stage-specific duration of $\mathrm{AD}$ is needed to inform patients, caregivers, and clinicians. This information is also useful for the design of clinical studies, as well as to provide context for the interpretation of trial results, in particular, the clinical trials that include individuals in predementia stages and aim to slow down progression to AD dementia.

Attempts to quantify the duration of AD should be age specific because age imposes the greatest risk for both dementia and mortality, and take into account apolipoprotein $\mathrm{E}(A P O E)$ genotype, sex, and cerebrospinal fluid (CSF) tau levels [4,6,10-12]. Setting is also important as progression from mild cognitive impairment to dementia was longer in research settings than in clinical settings [13]. Previous studies on the length of the AD dementia stage reported a duration of 3-10 years [14,15]. Younger age, female sex, and lower CSF total tau (t-tau) were found to be associated with a longer duration of the $\mathrm{AD}$ dementia stage, whereas the effect of $A P O E$ genotype was equivocal [14-17]. The median duration of prodromal $\mathrm{AD}$ was 3 years in a pooled memory clinic cohort study, but no age-specific estimates were provided and mortality was not taken into account [18]. The patients with prodromal AD and increased CSF t-tau levels tended to convert sooner to AD dementia $[19,20]$. The duration of the preclinical AD stage has been estimated in combination with the prodromal AD stage, which was 17 years, based on extrapolations of change in positron emission tomography amyloid load over time [21].

We estimated disease duration by applying a multistate modeling approach, which has been previously used in $\mathrm{AD}$ research [22-25], and can offer an estimate of disease duration based on stage progression and mortality rates in the absence of very long follow-up duration. The aim of this study was therefore to estimate the disease duration for preclinical, prodromal, and $\mathrm{AD}$ dementia stage according to age, setting (clinical vs. research), sex, APOE genotype, and baseline CSF t-tau levels.

\section{Methods}

\subsection{Participants}

Six longitudinal cohort studies, including three memory clinic cohorts (Amsterdam Dementia Cohort [ADC], Development of Screening Guidelines and Criteria for Predementia Alzheimer's Disease [DESCRIPA], and Impact of Cholinergic Treatment Use [ICTUS]) and three research cohorts (Alzheimer Disease Neuroimaging Initiative [ADNI], Australian Imaging, Biomarker \& Lifestyle Flagship Study of Aging [AIBL], and Prospective Population Study of Women in Gothenburg H70 [Gothenburg H70]), provided data for the study (see Supplementary Material A for more cohort information) [26-31]. From these cohorts, we selected participants aged 50 years and older with evidence of amyloid accumulation and with information on diagnosis and/or mortality at follow-up available. Evidence of amyloid pathology was an inclusion criterion for this study, defined by at least one abnormal marker of amyloid accumulation. The amyloid positron emission tomography scans were visually rated or a published threshold was applied, and for CSF amyloid- $\beta 1-42\left(\mathrm{~A} \beta_{1-42}\right)$, cohort-specific thresholds were applied (Supplementary Material A). In absence of amyloid measures for the ICTUS cohort, only the patients with a clinical diagnosis of AD-type dementia were included and analyses repeated without this cohort. All studies were approved by an ethical review board, and their participants gave informed consent. 


\subsection{AD stages}

AD was categorized into four clinical stages: preclinical $\mathrm{AD}$, prodromal $\mathrm{AD}$, mild $\mathrm{AD}$ dementia, and moderate-tosevere AD dementia (from here on shortened to moderate AD dementia). Preclinical AD was defined by amyloid accumulation and normal cognition (Supplementary Material A). Prodromal AD was in this study defined by amyloid accumulation and a diagnosis of mild cognitive impairment, amnestic and nonamnestic [9,32,33]. AD dementia was diagnosed according to the National Institute of Neurological Disorders and Stroke-Alzheimer Disease and Related Disorders criteria, and if an amyloid evaluation was available, this had to be confirmative [7]. $\mathrm{AD}$ dementia was subdivided into mild $\mathrm{AD}$ dementia (Clinical Dementia Rating [CDR] below 2, or CDR sum of boxes $<10$, or (if no CDR was available) MiniMental State Examination $>20$ ) and moderate AD dementia (CDR $>1$, CDR sum of boxes $>9$, or (if no CDR was available) Mini-Mental State Examination < 21) [34,35].

\subsection{Mortality assessment}

The ADC mortality data were obtained from the Dutch population register, whereas the other studies provided mortality data recorded during the study. In AIBL, the exact mortality date of those who died was unknown $(n=19)$ and therefore set at the next planned visit, which is 1.5 years after the last follow-up. In others cases of a missing mortality date $(n=4)$, the date was set 2 years after the last follow-up.

\subsection{Predictor variables}

For all participants, age, sex, and setting were available. The setting was classified as clinical for ADC, DESCRIPA, and ICTUS, and research for ADNI, AIBL, and Gothenburg H70. APOE genotype was dichotomized according to the presence or absence of the $\mathrm{AD}$-associated $\varepsilon 4$ allele of $A P O E$ and was available in all cohorts except ICTUS. Baseline CSF t-tau was classified as normal or abnormal by applying the cohort-specific cutoff and available for the ADC, DESCRIPA, ADNI, and Gothenburg H70 studies (Supplementary Material A).

\subsection{Statistical analyses}

Baseline characteristics between diagnostic groups were compared using $\chi^{2}$, Kruskal-Wallis, or analysis of variance tests with Tukey post hoc, where appropriate. To estimate the disease duration, a multistate model (MSM) with the four stages of $\mathrm{AD}$ and death as the end stage was fitted [36]. All transition rates between stages were incorporated in one model (Fig. 1). Reversions from prodromal to preclinical AD were also included in the model. Reversions in the dementia stages were fitted using misclassification (see Supplementary Material B for additional methods and specifications of MSM analysis).

MSMs with different numbers of covariates were fitted to the data. Age was a time-dependent covariate and centered at age 70 years. For each covariate, a hazard ratio was calculated for each transition. As most covariate effects on mortality were not estimable, a restricted model was applied. The first model included only age as covariate, the second model included setting as well, and the third model had age, setting, and sex as covariates. The fourth model included age, setting, and $A P O E$, whereas the fifth model had age, setting, and tau as covariates, and the sixth model included all five covariates. As not all covariates were available for all participants, the number of participants varied between models. The resulting transition rates and hazard ratios are based on every observation of every participant in combination with the time in between the observations.

In a second step, using the MSM maximum likelihood estimate as input, the duration for every stage was estimated. Confidence intervals (CIs) of $95 \%$ were derived by simulation using the asymptotic properties of the maximum likelihood estimation, which allowed comparison between age-specific estimates for the different covariates. R-packages $m s m$ for the multistate transition model and ELECT, version 0.3, (estimating life-expectancies for interval censored data) were used to estimate the duration estimates and CIs [36,37]. Sensitivity analyses included, aside of fitting all covariates in one model, sequentially removing cohorts from the analysis to ensure results were not driven by a single cohort. We also reran all models in the subset with data on all covariates $(n=1518)$.

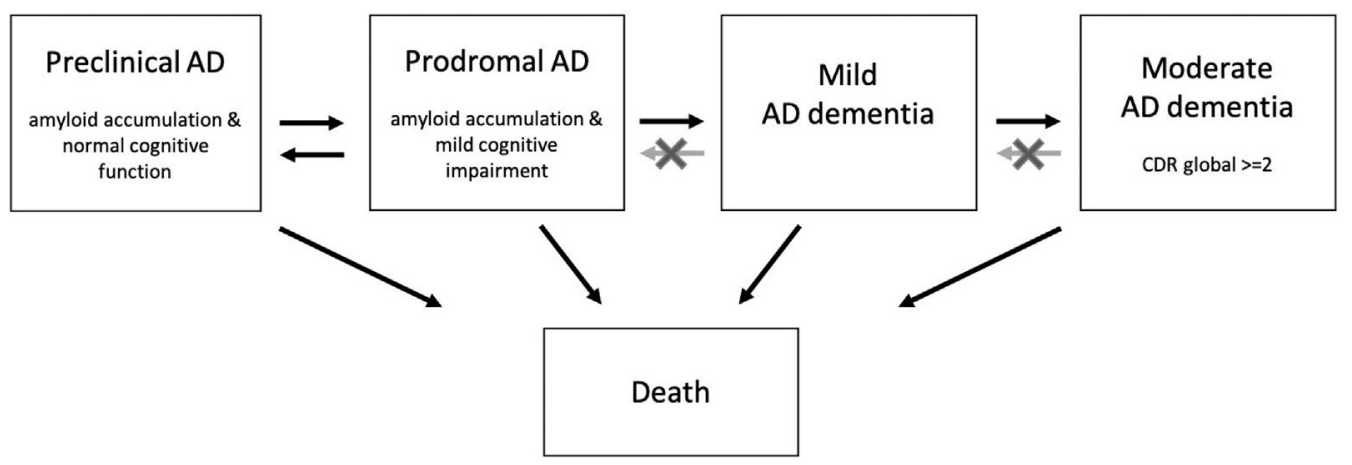

Fig. 1. Multistate model. Arrows indicate fitted progression and reversion rates between stages in the multistate model. Moderate-to-severe AD dementia is shortened to moderate AD dementia for readability. Abbreviation: AD, Alzheimer's disease. 
Table 1

Baseline characteristics according to diagnosis

\begin{tabular}{|c|c|c|c|c|c|}
\hline Characteristics & $\begin{array}{l}\text { Preclinical AD } \\
(\mathrm{n}=438)\end{array}$ & $\begin{array}{l}\text { Prodromal AD } \\
(\mathrm{n}=729)\end{array}$ & $\begin{array}{l}\text { Mild AD dementia } \\
(\mathrm{n}=1867)\end{array}$ & $\begin{array}{l}\text { Moderate-to-severe } \\
\text { AD dementia } \\
(\mathrm{n}=234)\end{array}$ & $\begin{array}{l}P \text { value overall } \\
\text { group difference }\end{array}$ \\
\hline Male (n) & $204(47 \%)$ & $417(57 \%)$ & $781(42 \%)$ & $74(33 \%)$ & $<0.01$ \\
\hline $\begin{array}{l}\text { MMSE }[0-30, \text { median } \\
\quad \text { (interquartile range) }(\mathrm{n}=3252)\end{array}$ & $29(28-30)$ & $27(26-29)$ & $22(19-24)$ & $16(13-19)$ & $<0.01^{\dagger}$ \\
\hline$A P O E$ \& 4 allele carrier ${ }^{\ddagger}(\mathrm{n})(\mathrm{n}=1984)$ & $210(49 \%)$ & $466(66 \%)$ & $554(71 \%)$ & $35(51 \%)$ & $<0.01$ \\
\hline $\begin{array}{l}\text { Follow-up years [median (interquartile } \\
\text { range)] }\end{array}$ & $3.8(2-4.5)$ & $3.9(2.5-4.8)$ & $2.0(1.5-2.5)$ & $2.0(1.2-2.3)$ & $<0.01^{\S}$ \\
\hline $\begin{array}{l}\text { Progression to next clinical } \\
\text { disease stage }(\mathrm{n})\end{array}$ & $87(20 \%)$ & $325(45 \%)$ & $569(30 \%)$ & NA & NA \\
\hline Death at follow-up (n) & $12(3 \%)$ & $76(10 \%)$ & $215(12 \%)$ & $54(23 \%)$ & NA \\
\hline $\begin{array}{l}\text { Participants by cohort } \\
\text { (n, ADC/ADNI/AIBL/DESCRIPA/ } \\
\text { Gothenburg/ICTUS) }\end{array}$ & $40 / 180 / 191 / 23 / 4 / 0$ & $140 / 449 / 73 / 49 / 18 / 0$ & $507 / 224 / 69 / 0 / 1 / 1066$ & $64 / 1 / 3 / 0 / 0 / 166$ & NA \\
\hline
\end{tabular}

NOTE. Values are in mean (standard deviation), unless otherwise specified.

Abbreviations: APOE, apolipoprotein E; AD, Alzheimer's disease; MCI, mild cognitive impairment; MMSE, Mini-Mental Status Examination; CSF, cerebrospinal fluid; ADC, Amsterdam Dementia Cohort; ADNI, Alzheimer Disease Neuroimaging Initiative; AIBL, Australian Imaging, Biomarker \& Lifestyle Flagship Study of Aging.

*Patients with moderate-to-severe AD dementia were older than those with MCI and mild AD dementia in the Tukey post hoc test.

${ }^{\dagger}$ All groups are significantly different from each other in the Tukey post hoc test.

${ }^{\ddagger}$ Available in subset of cohorts, $A P O E$ not for ICTUS.

${ }^{\S}$ Normal cognition and MCI group had longer follow-up than dementia groups in the Tukey post hoc test.

\section{Results}

A total of 3268 participants were included in the analyses across the six cohorts combined. The mean (standard deviation) age at baseline was 73 (8) years with a range of 50 to 96 years. The mean (standard deviation) number of followup years was 2.8 (1.9) with a range of 0.3 to 20 years, and a median (interquartile range) number of 4 (3-5) visits. Progression to at least one consecutive stage was apparent in 981 (32\% of 3034) participants. Table 1 shows how participants in the baseline stages differed in sex, $A P O E$ \&4 allele carriership, abnormal CSF t-tau, follow-up length, and mortality (Supplementary Table B5 for subgroups with data on $A P O E$ and CSF t-tau available).

\subsection{Transition rates}

In the model that included age, sex, and setting, all transition rates to subsequent disease were significantly influenced by age, except mortality in the preclinical AD stage and progression from prodromal $\mathrm{AD}$ to mild $\mathrm{AD}$ dementia (Supplementary Table B2 for all estimates of the models). Compared with data collected in a research setting, data from clinical settings were associated with a higher progression rate (hazard ratio $[\mathrm{HR}]=4.40$ [95\% CI, 2.80-6.94]) and reversion rate $(\mathrm{HR}=1.98$ [95\% CI, 1.15-3.39]) between preclinical and prodromal AD. In addition, in the clinical setting, the progression rates from the prodromal $\mathrm{AD}$ to the mild AD dementia stage (HR $=1.48$ [95\% CI, 1.341.92]) and from the mild $\mathrm{AD}$ to the moderate $\mathrm{AD}$ dementia stage $(\mathrm{HR}=1.41$ [95\% CI, 1.16-1.72]) were higher. $\mathrm{Fe}$ - males had a higher progression rate from mild AD to moderate $\mathrm{AD}$ dementia than males (HR $=1.24$ [95\% CI, 1.041.47]), whereas their mortality risk in moderate $\mathrm{AD}$ dementia was lower (HR $=0.60$ [95\% CI, 0.46-0.80]).

\subsection{AD stage duration according to age, sex, and setting}

The predicted total disease duration, based on the model with age, for an individual with preclinical $\mathrm{AD}$ at age 70 was 20 years $(95 \%$ CI, 17-21), consisting of a preclinical stage of 10 years $(95 \% \mathrm{CI}, 8-11)$, followed by a prodromal stage of 4 years $(95 \% \mathrm{CI}, 3-5)$, mild AD dementia for 3 years $(95 \% \mathrm{CI}, 2-3)$, and moderate AD dementia for 3 years $(95 \%$ CI, 2-3, Table 2). Fig. 2A shows for those with preclinical $\mathrm{AD}$ a lower predicted overall disease duration at older age, which ranged from 24 years (95\% CI, 22-25) at age 60 to 15 years $(95 \%$ CI, 11-17) at age 80. The duration of preclinical AD at age 70 was shorter in a clinical setting (4 years [95\% CI, 3-5]) than in a research setting (11 years [95\% CI, 9-13]). In the clinical setting, for individuals with prodromal $\mathrm{AD}$, the stage duration of prodromal $\mathrm{AD}$ was also shorter, and although the dementia stage duration for these individuals was equal between settings, more time was spent in the moderate AD stage (Supplementary Table $\mathrm{B} 7 \mathrm{a}$ and $\mathrm{b}$ ). The estimated total duration with starting stage preclinical $\mathrm{AD}$ ranged in the clinical setting from 19 years (95\% CI, 17-20) at age 60 to 11 years (95\% CI, 10-12) at age 80 and in the research setting from 26 years (95\% CI, 23-28) at age 60 to 15 years $(95 \%$ $\mathrm{CI}, 12-17)$ at age 80 . In females, the moderate $\mathrm{AD}$ 
Table 2

Estimated stage-specific duration of $\mathrm{AD}$

\begin{tabular}{|c|c|c|c|c|}
\hline Starting stage & Duration, time in years $(95 \% \mathrm{CI})$ & Age 60 & Age 70 & Age 80 \\
\hline & Prodromal AD & $4.4(3.7,4.8)$ & $4.0(3.3,4.7)$ & $3.5(2.3,4.5)^{*}$ \\
\hline & Moderate AD dementia & $3.5(2.8,4.1) \S$ & $2.6(2.1,3.3)$ & $1.7(1.1,2.4) \S$ \\
\hline & Total duration & $24.1(21.8,25.4)$ & $19.5(17.3,20.8)$ & $15.0(11.0,16.9)$ \\
\hline \multirow[t]{4}{*}{ Prodromal AD } & Preclinical AD & $3.2(2.2,4.3) \ddagger$ & $1.6(1.1,2.1)$ & $0.7(0.4,1.2) \S$ \\
\hline & Prodromal AD & $4.6(4.0,5.3)$ & $4.4(3.9,4.8)$ & $4.0(3.4,4.7)$ \\
\hline & Moderate AD dementia & $4.9(4.2,5.5) \S$ & $3.9(3.3,4.5)$ & $2.7(2.2,3.5) \S$ \\
\hline & Total duration & $17.2(15.8,18.3)$ & $13.6(12.7,14.5)$ & $10.3(9.3,11.5)$ \\
\hline \multirow[t]{3}{*}{ Mild AD dementia } & Mild AD dementia & $5.0(4.3,5.7) \dagger$ & $4.3(4.0,4.7)$ & $3.6(3.2,3.9) \S$ \\
\hline & Moderate AD dementia & $6.0(5.1,6.7) \ddagger$ & $4.8(4.2,5.5)$ & $3.6(3.0,4.5) \S$ \\
\hline & Total duration & $10.9(10.1,11.8)$ & $9.0(8.4,9.7)$ & $7.1(6.4,7.9)$ \\
\hline Moderate $\mathrm{AD}$ dementia & Moderate AD dementia & $6.5(5.4,7.5) \ddagger$ & $5.2(4.0,6.0)$ & $4.1(3.5,5.1) \ddagger$ \\
\hline
\end{tabular}

NOTE. Estimates based on model including age as a covariate (Model 1 in Supplementary Table B2). Stage estimates are significantly different from estimates at age 70 .

Abbreviations: Moderate AD dementia, moderate-to-severe AD dementia; AD, Alzheimer's disease; CI, confidence interval.

$* P<.05$.

${ }^{\dagger} P<.01$.

${ }^{\ddagger} P<.001$.

${ }^{\S} P<.0001$.

dementia stage duration was longer than in males (e.g., 2.1 years [95\% CI, 1.1-3.2], $P<.0001$ at age 70 in a clinical setting; Fig. 2B, Supplementary Table B3).

\subsection{APOE effect}

$A P O E \varepsilon 4$ carriers had, compared with noncarriers, an increased rate of progression from the preclinical AD to prodromal AD stage $(\mathrm{HR}=1.63$ [95\% CI, 1.11-2.41]) and from the prodromal $\mathrm{AD}$ to mild $\mathrm{AD}$ dementia stage $(\mathrm{HR}=1.50$ [95\% CI, 1.18-1.90]), and a trend for slower decline from the mild to the moderate AD dementia stage (HR 0.77 [95\% CI, 0.60-1.00]). When compared with a noncarrier, an $A P O E$ \&4 carrier aged 70 years in the clinical setting had a 1.6 years $(95 \% \mathrm{CI}, 0.4-3.3 ; P=.0295)$ shorter estimated preclinical $\mathrm{AD}$ stage duration and 1.1 years $(95 \%$ CI, 0.3-2.1; $P=.0110$ ) shorter prodromal AD stage duration, but 1.0 year $(95 \% \mathrm{CI}, 0.3-1.8 ; P=.0050)$ longer mild dementia stage duration (Supplementary Table B4). Fig. 2C shows how the total predicted disease duration ranged from 12 to 25 years depending on APOE genotype, age, and setting.

\subsection{Tau effect}

As normal CSF t-tau level may become abnormal over time, only the estimated duration of the starting stages is presented in Table 3. Individuals with preclinical AD and abnormal CSF t-tau showed a trend for an increased progression rate from preclinical to prodromal $\mathrm{AD}(\mathrm{HR}=1.49$ [95\% CI, 0.95-2.35]). In prodromal AD, abnormal tau associated with a decreased reversion rate to preclinical AD stage $(\mathrm{HR}=0.41$ [95\% CI, 0.23-0.71] $)$ and increased progression rate to the mild $\mathrm{AD}$ dementia stage $(\mathrm{HR}=1.91$ [95\% CI, 1.48-2.48]). The estimated preclinical AD stage was shortened by around 3 years and the prodromal AD stage by around 2.5 years (Table 3 ). There was no association of baseline abnormal t-tau with the duration of the dementia stages.

\subsection{Sensitivity analyses}

Consecutively, removing each of the cohorts did not affect the estimates (Supplementary Table B6). When all variables were combined in one model, most estimates remained unchanged. In the additional analysis of the same models in the subset of individuals with all covariates $(\mathrm{n}=1518$, see Supplementary Table B8), the effects were similar. Varying the mortality assumptions for unknown mortality dates of those who died did not change the results.

\section{Discussion}

We estimated the duration of the preclinical, prodromal, mild dementia, and moderate dementia stages of AD using an MSM. Depending on age, sex, APOE genotype, baseline CSF t-tau, and setting, the total disease duration varied between 12 and 25 years, the preclinical stage between 2 and 15 , the prodromal stage between 3 and 7, mild AD dementia stage between 2 and 6 , and moderate AD dementia stage between 1 and 7 years.

\subsection{Effect of age}

Age had the strongest effect on the duration of the preclinical and dementia stages, which could be explained by higher progression and mortality rates. The decrease of 

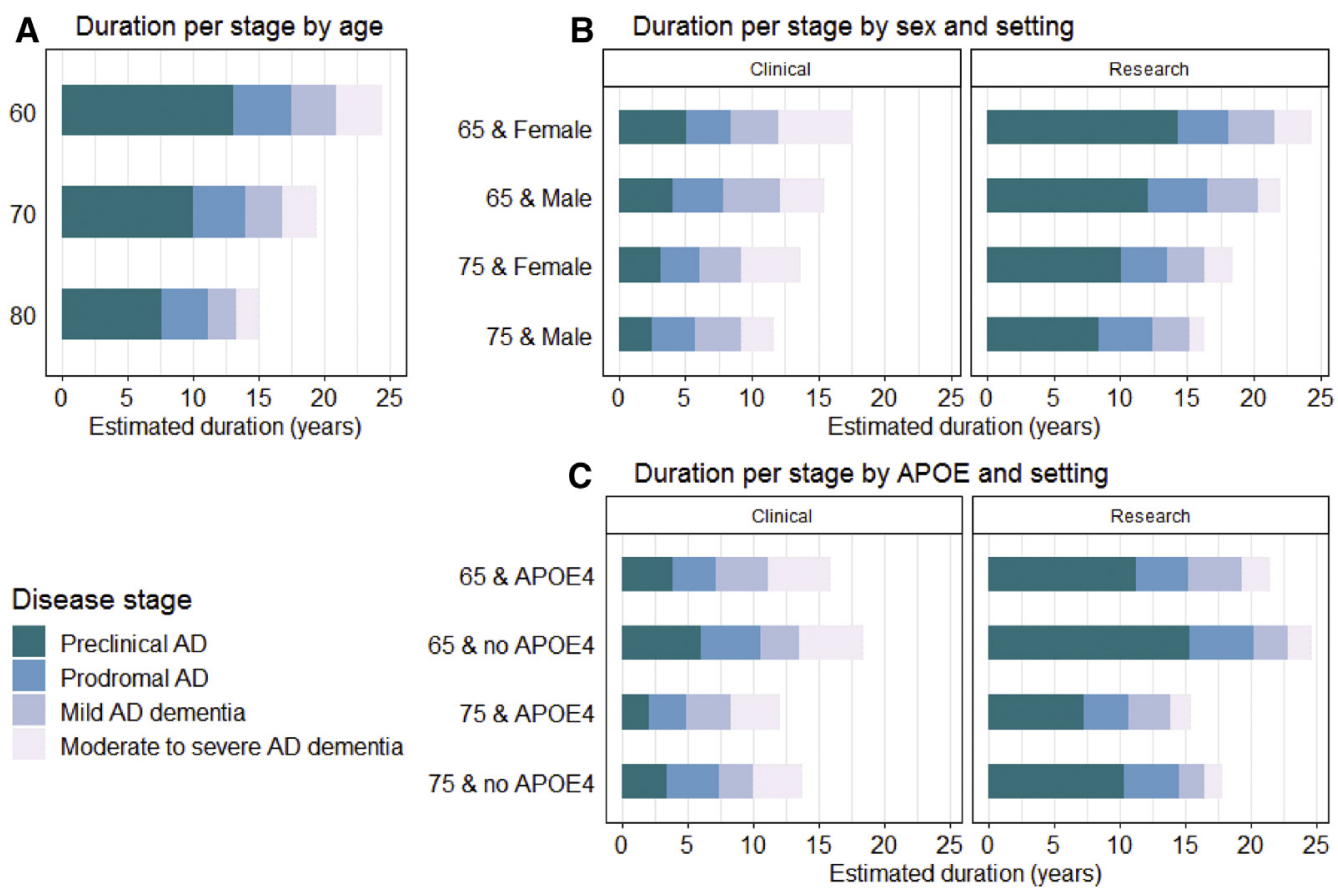

Fig. 2. Estimated stage-specific duration for starting stage preclinical AD. The panels show the predicted time spend in each stage stacked and stratified for (A) age (model 1); for (B) age, sex, and setting (model 3); and for (C) age, APOE genotype, and setting (model 4). Models include age as a continuous covariate, and (B) sex and setting or (C) APOE and setting as dichotomous covariates. The age refers to the starting stage with preclinical AD, and the estimated duration, the predicted duration in the subsequent stages in years. The 95\% confidence intervals and $P$ values for estimate comparison can be found for (A) in Table 2, for panel (B) in Supplementary Table B3, and for panel (C) in Supplementary Table B4. Abbreviations: AD, Alzheimer's disease; APOE, apolipoprotein E.

disease duration of the preclinical $\mathrm{AD}$ stage could also be due to a reduction in resilience to AD pathology at higher age, for example, due to comorbid brain disorders, resulting in a faster clinical progression [38]. Alternatively, older individuals may have spent a longer period in the preclinical AD stage before inclusion in the study. Our estimated duration of the combined preclinical and prodromal stage for a 70-year-old (17 years) was very similar to the estimated duration of 17 years predementia $\mathrm{AD}$ based on differential equation modeling of the amyloid accumulation rate in individuals aged 72 years on average [21].

\subsection{Effect of setting}

The shorter duration of the preclinical and prodromal stage in the clinical compared with the research setting could be explained by the fact that individuals who present in a clinical setting are in a more advanced stage of the disease. An alternative explanation is that individuals who present in a clinical setting have a more aggressive disease form, whereas those with a slower progressive variant would be picked up in the research setting [39]. The estimated differences between settings may be underestimated in the present study, as part of the individuals from the AIBL and ADNI research cohorts were recruited in memory clinics. The effects of setting on disease progression are consistent with other AD studies $[40,41]$.

\subsection{Effect of APOE genotype}

The shorter age-specific duration of the preclinical stage in $A P O E \varepsilon 4$ carriers is consistent with the observed earlier onset of dementia due to $\mathrm{AD}$ in epidemiological studies and the faster cognitive decline of $A P O E \& 4$ carriers with preclinical AD in research studies [11,42-44]. Although the prodromal stage was shorter in APOE $\& 4$ carriers, the dementia stage was longer, which would imply that the total symptomatic disease duration is similar but differently divided over the stages. These findings are important for clinical trials. For example, exclusion of $\varepsilon 4$ carriers during a trial, what happened in the high-dose group of the BAN2401 trial, may affect rate of progression and possibly the power of the study [45].

\subsection{Effect of sex}

The dementia stage duration was longer in women, which was driven by lower mortality in this group. The study did not reveal significant sex differences in the duration of preclinical and prodromal AD stages.

\subsection{Effect of tau}

The presence of increased CSF t-tau was associated with a shorter predementia disease duration, which confirms that increased tau is associated with faster disease progression. 
Table 3

Estimated stage-specific duration stratified for baseline CSF total tau by setting at age 70

\begin{tabular}{|c|c|c|c|c|c|c|c|}
\hline \multirow[b]{2}{*}{ Starting stage } & \multirow[b]{2}{*}{$\begin{array}{l}\text { Duration in } \\
\text { years }(95 \% \mathrm{CI})\end{array}$} & \multicolumn{3}{|c|}{ Clinical setting } & \multicolumn{3}{|l|}{ Research setting } \\
\hline & & Tau normal & $\begin{array}{l}\text { Tau } \\
\text { abnormal }\end{array}$ & $\begin{array}{l}\text { Difference } \\
\text { (95\% CI; } P \text { value) }\end{array}$ & Tau normal & $\begin{array}{l}\text { Tau } \\
\text { abnormal }\end{array}$ & $\begin{array}{l}\text { Difference } \\
\text { (95\% CI; } P \text { value) }\end{array}$ \\
\hline Preclinical AD & Preclinical AD & $5.6(3.7,8.9)$ & $3(1.9,4.3)$ & $2.6(0.7,5.5 ; P=.034)$ & $11.6(8.3,14.3)$ & $7.7(5.6,9.9)$ & $3.7(0.4,7.3 ; P=.033)$ \\
\hline Prodromal AD & Prodromal AD & $5.4(4.0,7.0)$ & $3(2.3,3.7)$ & $2.4(1.2,3.7 ; P=.0002)$ & $6.8(5.5,8.1)$ & $3.9(3.3,4.6)$ & $2.9(1.4,4.2 ; P=.0001)$ \\
\hline $\begin{array}{l}\text { Mild AD } \\
\text { dementia }\end{array}$ & $\begin{array}{l}\text { Mild AD } \\
\text { dementia }\end{array}$ & $4.4(3.2,5.9)$ & $3.6(2.9,4.4)$ & $0.8(-0.4,2.2 ; P=.230)$ & $6.4(4.7,7.9)$ & $5.4(4.2,6.5)$ & $1.1(-0.5,2.7 ; P=.197)$ \\
\hline $\begin{array}{l}\text { Moderate AD } \\
\text { dementia }\end{array}$ & $\begin{array}{c}\text { Moderate AD } \\
\text { dementia }\end{array}$ & $4.9(3.1,7.7)$ & $5.9(4.1,8.7)$ & $-0.9(-3.0,1.6 ; P=.439)$ & $2.8(1.8,4.1)$ & $3.5(2.5,4.7)$ & $-0.6(-2.0,1.0 ; P=.438)$ \\
\hline
\end{tabular}

NOTE. Estimates based on model including age as a continuous covariate and baseline CSF t-tau and setting as dichotomous covariates (Model 5 in Supplementary Table B2).

Abbreviations: AD, Alzheimer's disease; CSF, cerebrospinal fluid; moderate AD, moderate-to-severe AD; Tau, baseline CSF total tau; CI, confidence interval.

Unlike previous studies, no effect of tau on mortality and duration of the $\mathrm{AD}$ dementia stage were found, which may be explained by dichotomization of CSF t-tau in our analysis $[16,17]$.

\subsection{Duration and mortality}

The estimation of total disease duration estimates were in some cases longer than the residual life expectancies of population data [46]. For example, the residual life expectancy at age 80 was reported to be $8-10$ years in the USA and Australia (data from 2010 to 2012), whereas in our study, this ranged from 4 years for those with moderate $\mathrm{AD}$ to 15 years for individuals with preclinical AD. One explanation for the longer duration is that we may have overestimated disease duration because mortality had not been checked systematically in all studies. On the other hand, mortality rates in our study cohorts may also be lower because both volunteers participating in studies and memory clinic patients may be healthier at study entry than individuals not participating in research or attending memory clinics.

\subsection{Strengths and limitations}

A strength of the study is the large sample of participants with amyloid accumulation. The MSM approach is another strength because it enabled the incorporation of multiple clinical stages, including fluctuations between stages, and the mortality risk in a data-driven manner. A limitation of the modeling approach is the underlying assumption that progression risk is independent on the previous time spend in a stage, whereas progression risk may actually change after being in a stage for a longer period of time. This was addressed by taking age as the time-dependent covariate, which has been applied before to overcome this issue $[22,47]$. To estimate the disease duration, we had to combine data of multiple cohorts across the disease spectrum. As such, the sample consisted of over 3000 individuals, still not all the effects were estimable. Combining cohort data leads to heterogeneity, that is, due to different application of diagnostic criteria, cognitive testing, and amyloid status. Another limitation was that amyloid status and $A P O E$ genotype were unknown for patients with AD-type dementia of the ICTUS study, but the sensitivity analysis without those in the ICTUS study yielded very similar results. In addition, we used the old criteria for the preclinical AD definition, whereas the recent research criteria also require tau positivity [8]. Finally, our sample is not representative of the general population but may be representative of the patients who physicians need to inform and volunteers who participate in clinical trials.

\subsection{Implications}

Our estimates are of practical use to clinicians needing to provide prognostic information to research participants and patients. For instance, in a research study with disclosure of abnormal amyloid status, these estimates can give an indication of the prognosis, often asked for by the trial participants before joining the study. The estimates of AD duration are also useful to define target populations for trials. Furthermore, these estimates can be used to indicate how a preventive treatment in the early stage of the disease could impact total disease duration.

\section{Conclusion}

We provided age-specific disease estimates of the duration of $\mathrm{AD}$, including the long predementia stage, according to setting, sex, APOE genotype, and presence of tau pathology. Our findings will be useful to provide patients a prognosis, to inform clinical trial design, and can help to model how interventions in early-stage AD may influence longterm outcome.

\section{Acknowledgments}

The authors are very thankful to all patients and participants in the studies included in this study, as well as to everyone involved in the data collection and data sharing. 
ICTUS study group refers to Vellas B., Reynish E., Ousset PJ., Andrieu S. (Toulouse), Burns A. (Manchester), Pasquier F. (Lille), Frisoni G. (Brescia), Salmon E. (Liège), Michel J.P., Zekry D.S. (Geneva), Boada M. (Barcelona), Dartigues J.F. (Bordeaux), Olde-Rikkert M.G.M. (Nijmegen), Rigaud A.S. (Paris), Winblad B. (Huddinge), Malick A., Sinclair A. (Warwick), Frölich L.(Mannheim), Scheltens P. (Amsterdam), Ribera C.(Madrid), Touchon J. (Montpellier), Robert P. (Nice), Salva A. (Barcelona), Waldemar G. (Copenhagen), Bullock R. (Swindon), Tsolaki M. (Thessaloniki), Rodriguez G. (Genoa), Spiru L. (Bucharest), Jones R.W. (Bath), Stiens G., Stoppe G. (Göttingen), Eriksdotter Jönhagen M. (Stockholm), Cherubini A. (Perugia), Lage P.M., GomezIsla T. (Pamplona), Camus V. (Tours), Agüera-Morales E., and Lopez F. (Cordoba).

DSA group refers to Andrieu S., Savy S., Cantet C., and Coley N.

Kern, Wallin, Olde Rikkert, Ousset, Spiru, Freund-Levi, Tsolaki, Muniz-Terrera, and van den Hout report no disclosures. Vermunt, Sikkes, Visser, and Handels report grants from European Brain Council (VoT project; 2017). Dr Bos has received research support from the Innovative Medicines Initiatives Joint Undertaking under resources that are composed of financial contributions from EU FP7 (FP7/ 2007-2013) and in-kind EFPIA. Ron Handels reports grants from BIOMARKAPD (EU JPND; 2012-2016), Actifcare (EU JPND; 2014-2017), Dutch Flutemetamol Study (20122017), ROADMAP (IMI2; 2016-2019), SNAC (Sweden public funding; 2016-2018), MIND-AD (EU JPND; 20172018), Alzheimer Association Nederland (NL fellowship; 2017-2019), Economic and Policy Implications of new treatment for AD (ARUK; 2017-2018), various ZonMw projects (NL public funding; 2017-2022), and RECAGE (EU H2020; 2018-2022) and personal fees from Piramal (advisory; 2016) and Roche (advisory; 2017). Research programs of Dr van der Flier have been funded by ZonMw, the Netherlands Organization of Scientific Research, Seventh European Framework Program, Alzheimer Nederland, Cardiovascular Onderzoek Nederland, Stichting Dioraphte, Gieskes, Strijbis fonds, Boehringer Ingelheim, Piramal Imaging, Roche BV, Janssen Stellar, and Combinostics. All funding is paid to her institution. Skoog reports consultant fee for Takeda. Dr Scheltens has acquired grant support (for the institution) from GE Healthcare, Danone Research, Piramal, and Merck. In the past 2 years, he has received consultancy/speaker fees (paid to the institution) from Lilly, GE Healthcare, Novartis, Sanofi, Nutricia, Probiodrug, Biogen, Roche, Avraham, and EIP Pharma. Paul Maruff is an employee of Cogstate Ltd. Frans RJ Verhey received grants from H2020 Induct (2016-2020), Pride Alzheimer UK (2015-2020), Actifcare (EU JPND; 2014-2017), Gieskes-Strijbis (PRECODE 2018-2022), Noaber Foundation (INPAD 2017-2021), and Interreg (SFC, 2016-202). Hilkka Soininen reports advisory board member for ACImmune and MERCK. Kaj Blennow is a advisor for Fujirebio Europe, IBL International, and Roche Diagnostics and a cofounder of Brain Biomarker Solutions in Gothenburg AB, a GU Ventures-based platform company at the University of Gothenburg. Henrik Zetterberg is a cofounder of Brain Biomarker Solutions in Gothenburg $\mathrm{AB}$, a GU Ventures-based platform company at the University of Gothenburg. Dr. Visser reports grants from Innovative Medicine Initiative, during the conduct of the study; nonfinancial support from GE Healthcare, other from Eli-Lilly, Janssen Pharmaceutical, grants from Biogen, and outside the submitted work.

Funding support: Funders had no role in study design, data analysis, data interpretation, or writing of the report. The work was supported by the IALSA (Integrative Analysis of Longitudinal Studies of Aging and Dementia) network, which received support by NIH grant P01AG043362 (2013-2018); from the Innovative Medicines Initiative Joint Undertaking EMIF grant agreement number 115372, EPAD grant agreement number 115736, resources, and ROADMAP grant agreement number 116020 of which are composed of financial contribution from the European Union's Seventh Framework Program (FP7/2007-2013) and EFPIA companies' in-kind contribution; and the European Brian Council.

Funding for each of the studies.

$A D C$ : The VU University Medical Center (VUMC) Alzheimer Center is supported by Alzheimer Nederland and Stichting VUMC funds. This study was performed within the framework of the Dutch ABIDE project and was supported by a ZonMW-Memorabel grant (project No 733050201) in the context of the Dutch Deltaplan Dementie and through a grant of Piramal Imaging (positron emission tomography scan costs) to the Stichting Alzheimer en Neuropsychiatrie, Amsterdam. Research of the VUMC Alzheimer Center is part of the neurodegeneration research program of Amsterdam Neuroscience. The clinical database structure was developed with funding from Stichting Dioraphte.

ADNI: Data collection and sharing for this project was funded by the Alzheimer's Disease Neuroimaging Initiative (ADNI) (National Institutes of Health Grant U01 AG024904) and DOD ADNI (Department of Defense award number W81XWH-12-2-0012). ADNI is funded by the National Institute on Aging, the National Institute of Biomedical Imaging and Bioengineering, and through generous contributions from the following: AbbVie; Alzheimer's Association; Alzheimer's Drug Discovery Foundation; Araclon Biotech; BioClinica, Inc.; Biogen; Bristol-Myers Squibb Company; CereSpir, Inc.; Cogstate; Eisai; Elan Pharmaceuticals, Inc.; Eli Lilly and Company; EuroImmun; F. Hoffmann-La Roche Ltd. and its affiliated company Genentech, Inc.; Fujirebio; GE Healthcare; IXICO Ltd.; Janssen Alzheimer Immunotherapy Research \& Development, LLC.; Johnson \& Johnson Pharmaceutical Research \& Development LLC.; Lumosity; Lundbeck; Merck \& Co., Inc.; Meso Scale Diagnostics, LLC.; NeuroRx Research; Neurotrack Technologies; Novartis Pharmaceuticals Corporation; Pfizer Inc.; Piramal Imaging; Servier; Takeda 
Pharmaceutical Company; and Transition Therapeutics. The Canadian Institutes of Health Research is providing funds to support ADNI clinical sites in Canada. Private sector contributions are facilitated by the Foundation for the National Institutes of Health (www.fnih.org). The grantee organization is the Northern California Institute for Research and Education, and the study is coordinated by the Alzheimer's Therapeutic Research Institute at the University of Southern California. ADNI data are disseminated by the Laboratory for NeuroImaging at the University of Southern California. AIBL: Funding for the AIBL study was provided in part by the study partners [Australian Commonwealth Scientific Industrial and research Organization (CSIRO), Edith Cowan University (ECU), Mental Health Research Institute (MHRI), Alzheimer's Australia (AA), National Aging Research Institute (NARI), Austin Health, CogState Ltd., Hollywood Private Hospital, and Sir Charles Gardner Hospital]. The study also received support from the National Health and Medical Research Council (NHMRC) and the Dementia Collaborative Research Centers program (DCRC2), as well as ongoing funding from the Science and Industry Endowment Fund (SIEF). The authors acknowledge the financial support of the Australian Government Cooperative Research Center for Mental Health.

DESCRIPA: The project was funded by the European Commission as part of the 5th Framework Program (QLK6-CT-2002-02455). The center in Bucharest received support from the Ana Aslan International foundation.

Gothenburg H70: The Swedish Research Council (201502830, 2013-8717); Swedish Research Council for Health, Working Life and Welfare (No 2013-2496, 2013-2300, 2010-0870, 2012-1138); Sahlgrenska University Hospital (ALF 716681); the Alzheimer's Association Zenith Award (ZEN-01-3151); the Alzheimer's Association Stephanie B. Overstreet Scholars (IIRG-00-2159); Alzheimerfonden; Hjärnfonden; and Konung Gustaf V:s och Drottning Victorias Frimurarestiftelse.

ICTUS/DSA: The ICTUS study was partially supported by a grant from the European Commission within the 5th framework program (QLK6-CT-2002-02645) and partially from an unrestricted equal grant from each of Eisai, Janssen, Lundbeck, and Novartis pharmaceutical companies. The pharmaceutical companies had no role in study design, data collection, data analysis, and data interpretation. Promotion of the ICTUS study was supported by the University Hospital Center of Toulouse. The data sharing activity was supported by the "Association Monegasque pour la recherche sur la maladie d'Alzheimer"(AMPA) and the UMR 1027 Unit INSERM-University of Toulouse III.

\section{Supplementary Data}

Supplementary data related to this article can be found at https://doi.org/10.1016/j.jalz.2019.04.001.

\section{RESEARCH IN CONTEXT}

1. Systematic review: Articles on the duration of each part of the Alzheimer's disease (AD) spectrum showed that the dementia stage was 3-10 years and the estimate of the preclinical and prodromal $\mathrm{AD}$ stage combined 17 years. Although several studies reported on the effect of age, sex, tau, and apolipoprotein $\mathrm{E}(A P O E)$ genotype on disease progression, this was not translated to subgroup- and agespecific disease duration estimates.

2. Interpretation: We improved previous estimates, by combining data from cognitive aging cohorts, to estimate the age-specific duration of preclinical, prodromal, and dementia stages of $\mathrm{AD}$ in a single multistate model, taking mortality into account, as well as age, sex, $A P O E$, and/or tau abnormality.

3. Future directions: Our findings are useful prognostic information for the different stages of $\mathrm{AD}$ and can help to select individuals for clinical trials and to model how interventions in early stage AD may influence long-term outcome. Long-term follow-up studies are needed to confirm our findings and are currently ongoing.

\section{References}

[1] Winblad B, Amouyel P, Andrieu S, Ballard C, Brayne C, Brodaty $\mathrm{H}$, et al. Defeating Alzheimer's disease and other dementias: a priority for European science and society. Lancet Neurol 2016;15:455-532.

[2] Scheltens P, Blennow K, Breteler MM, de Strooper B, Frisoni GB, Salloway S, et al. Alzheimer's disease. Lancet 2016;388:505-17.

[3] Fargo KN, Aisen P, Albert M, Au R, Corrada MM, DeKosky S, et al. 2014 Report on the milestones for the US National Plan to address Alzheimer's Disease. Alzheimers Demen 2014;10:S430-52.

[4] Jansen WJ, Ossenkoppele R, Knol DL, Tijms BM, Scheltens P, Verhey FR, et al. Prevalence of cerebral amyloid pathology in persons without dementia: a meta-analysis. JAMA 2015;313:1924-38.

[5] Jack CR Jr, Knopman DS, Jagust WJ, Petersen RC, Weiner MW, Aisen PS, et al. Tracking pathophysiological processes in Alzheimer's disease: an updated hypothetical model of dynamic biomarkers. Lancet Neurol 2013;12:207-16.

[6] Jack CR Jr, Bennett DA, Blennow K, Carrillo MC, Dunn B, Haeberlein SB, et al. NIA-AA Research Framework: Toward a biological definition of Alzheimer's disease. Alzheimers Dement 2018; 14:535-62.

[7] McKhann G, Drachman D, Folstein M, Katzman R, Price D, Stadlan EM. Clinical diagnosis of Alzheimer's disease: report of the NINCDS-ADRDA Work Group under the auspices of Department of Health and Human Services Task Force on Alzheimer's Disease. Neurology 1984;34:939-44.

[8] Sperling RA, Aisen PS, Beckett LA, Bennett DA, Craft S, Fagan AM. Toward defining the preclinical stages of Alzheimer's disease: recommendations from the National Institute on Aging-Alzheimer's 
Association workgroups on diagnostic guidelines for Alzheimer's disease. Alzheimers Dement 2011;7:280-92.

[9] Albert MS, DeKosky ST, Dickson D, Dubois B, Feldman HH, Fox NC, et al. The diagnosis of mild cognitive impairment due to Alzheimer's disease: recommendations from the National Institute on Aging-Alzheimer's Association workgroups on diagnostic guidelines for Alzheimer's disease. Alzheimers Dement 2011; 7:270-9.

[10] Neu SC, Pa J, Kukull W, Beekly D, Kuzma A, Gangadharan P, et al. Apolipoprotein E genotype and sex risk factors for Alzheimer disease: a meta-analysis. JAMA Neurol 2017;74:1178-89.

[11] Lim YY, Kalinowski P, Pietrzak RH, Laws SM, Burnham SC, Ames D, et al. Association of beta-amyloid and Apolipoprotein E epsilon4 with memory decline in preclinical alzheimer disease. JAMA Neurol 2018; 75:488-94.

[12] Vos SJ, Xiong C, Visser PJ, Jasielec MS, Hassenstab J, Grant EA, et al. Preclinical Alzheimer's disease and its outcome: a longitudinal cohort study. Lancet Neurol 2013;12:957-65.

[13] Farias ST, Mungas D, Reed BR, Harvey D, DeCarli C. Progression of mild cognitive impairment to dementia in clinic- vs community-based cohorts. Arch Neurol 2009;66:1151-7.

[14] Brodaty H, Seeher K, Gibson L. Dementia time to death: a systematic literature review on survival time and years of life lost in people with dementia. Int Psychogeriatr 2012;24:1034-45.

[15] Wattmo C, Londos E, Minthon L. Risk factors that affect life expectancy in Alzheimer's disease: a 15-year follow-up. Dement Geriatr Cogn Disord 2014;38:286-99.

[16] Rhodius-Meester HFM, Liedes H, Koene T, Lemstra AW, Teunissen CE, Barkhof F, et al. Disease-related determinants are associated with mortality in dementia due to Alzheimer's disease. Alzheimers Res Ther 2018;10:23.

[17] Degerman Gunnarsson M, Ingelsson $M$, Blennow $K$, Basun $H$, Lannfelt L, Kilander L. High tau levels in cerebrospinal fluid predict nursing home placement and rapid progression in Alzheimer's disease. Alzheimers Res Ther 2016;8:22.

[18] Vos SJ, Verhey F, Frolich L, Kornhuber J, Wiltfang J, Maier W, et al. Prevalence and prognosis of Alzheimer's disease at the mild cognitive impairment stage. Brain 2015;138:1327-38.

[19] van Rossum IA, Vos SJ, Burns L, Knol DL, Scheltens P, Soininen $\mathrm{H}$, et al. Injury markers predict time to dementia in subjects with MCI and amyloid pathology. Neurology 2012; 79:1809-16.

[20] Buchhave P, Minthon L, Zetterberg H, Wallin AK, Blennow K, Hansson O. Cerebrospinal fluid levels of beta-amyloid 1-42, but not of tau, are fully changed already 5 to 10 years before the onset of Alzheimer dementia. Arch Gen Psychiatry 2012; 69:98-106.

[21] Villemagne VL, Burnham S, Bourgeat P, Brown B, Ellis KA, Salvado O. Amyloid beta deposition, neurodegeneration, and cognitive decline in sporadic Alzheimer's disease: a prospective cohort study. Lancet Neurol 2013;12:357-67.

[22] Jack CR Jr, Therneau TM, Wiste HJ, Weigand SD, Knopman DS, Lowe VJ, et al. Transition rates between amyloid and neurodegeneration biomarker states and to dementia: a population-based, longitudinal cohort study. Lancet Neurol 2016;15:56-64.

[23] Robitaille A, van den Hout A, Machado RJM, Bennett DA, Cukic I, Deary IJ, et al. Transitions across cognitive states and death among older adults in relation to education: a multistate survival model using data from six longitudinal studies. Alzheimers Dement 2018; 14:462-72.

[24] Coley N, Gallini A, Gares V, Gardette V, Andrieu S, group ID. A longitudinal study of transitions between informal and formal care in Alzheimer disease using multistate models in the European ICTUS cohort. J Am Med Dir Assoc 2015;16:1104.e1-1104.e7.
[25] Brookmeyer R, Abdalla N, Kawas CH, Corrada MM. Forecasting the prevalence of preclinical and clinical Alzheimer's disease in the United States. Alzheimers Dement 2018;14:121-9.

[26] Weiner MW, Aisen PS, Jack CR Jr, Jagust WJ, Trojanowski JQ, Shaw L, et al. The Alzheimer's disease neuroimaging initiative: progress report and future plans. Alzheimers Dement 2010;6:202-211.e7.

[27] van der Flier WM, Pijnenburg YA, Prins N, Lemstra AW, Bouwman FH, Teunissen CE, et al. Optimizing patient care and research: the Amsterdam Dementia Cohort. J Alzheimers Dis 2014; 41:313-27.

[28] Reynish E, Cortes F, Andrieu S, Cantet C, Olde Rikkert M, Melis R, et al. The ICTUS Study: a Prospective longitudinal observational study of $1,380 \mathrm{AD}$ patients in Europe. Study design and baseline characteristics of the cohort. Neuroepidemiology 2007;29:29-38.

[29] Rowe CC, Ellis KA, Rimajova M, Bourgeat P, Pike KE, Jones G. Amyloid imaging results from the Australian Imaging, Biomarkers and Lifestyle (AIBL) study of aging. Neurobiol Aging 2010; 31:1275-83.

[30] Gustafson DR, Skoog I, Rosengren L, Zetterberg H, Blennow K. Cerebrospinal fluid beta-amyloid 1-42 concentration may predict cognitive decline in older women. J Neurol Neurosurg Psychiatry 2007; 78:461-4.

[31] Visser PJ, Verhey F, Knol DL, Scheltens P, Wahlund LO, FreundLevi Y, et al. Prevalence and prognostic value of CSF markers of Alzheimer's disease pathology in patients with subjective cognitive impairment or mild cognitive impairment in the DESCRIPA study: a prospective cohort study. Lancet Neurol 2009;8:619-27.

[32] Petersen RC, Smith GE, Waring SC, Ivnik RJ, Tangalos EG, Kokmen E. Mild cognitive impairment: clinical characterization and outcome. Arch Neurol 1999;56:303-8.

[33] Winblad B, Palmer K, Kivipelto M, Jelic V, Fratiglioni L, Wahlund LO, et al. Mild cognitive impairment-beyond controversies, towards a consensus: report of the International Working Group on mild cognitive impairment. J Intern Med 2004;256:240-6.

[34] O'Bryant SE, Waring SC, Cullum CM, Hall J, Lacritz L, Massman PJ, et al. Staging dementia using clinical dementia rating scale sum of boxes scores: a Texas Alzheimer's research consortium study. Arch Neurol 2008;65:1091-5.

[35] Perneczky R, Wagenpfeil S, Komossa K, Grimmer T, Diehl J, Kurz A. Mapping scores onto stages: mini-mental state examination and clinical dementia rating. Am J Geriatr Psychiatry 2006;14:139-44.

[36] Jackson Ch L. Multi-State models for panel data: the msm package for R. J Stat Softw 2011;38:1-29.

[37] Van den Hout A. Multi-State Survival Models for Interval-Censored Data 2017. Boca Raton: CRC/Chapman \& Hall; 2017.

[38] Vemuri P, Lesnick TG, Przybelski SA, Knopman DS, Lowe VJ, GraffRadford J, et al. Age, vascular health, and Alzheimer disease biomarkers in an elderly sample. Ann Neurol 2017;82:706-18.

[39] Croswell JM, Ransohoff DF, Kramer BS. Principles of cancer screening: lessons from history and study design issues. Semin Oncol 2010;37:202-15.

[40] Qian J, Wolters FJ, Beiser A, Haan M, Ikram MA, Karlawish J, et al. APOE-related risk of mild cognitive impairment and dementia for prevention trials: an analysis of four cohorts. PLos Med 2017; 14:e1002254.

[41] Snitz BE, Wang T, Cloonan YK, Jacobsen E, Chang CH, Hughes TF, et al. Risk of progression from subjective cognitive decline to mild cognitive impairment: the role of study setting. Alzheimers Dement 2018; 14:734-42.

[42] Roberts RO, Aakre JA, Kremers WK, Vassilaki M, Knopman DS, Mielke MM, et al. Prevalence and outcomes of amyloid positivity among persons without dementia in a longitudinal, population-Based setting. JAMA Neurol 2018;75:970-9. 
[43] van der Lee SJ, Wolters FJ, Ikram MK, Hofman A, Ikram MA, Amin N, et al. The effect of APOE and other common genetic variants on the onset of Alzheimer's disease and dementia: a community-based cohort study. Lancet Neurol 2018;17:434-44.

[44] Mormino EC, Betensky RA, Hedden T, Schultz AP, Ward A, Huijbers W, et al. Amyloid and APOE epsilon4 interact to influence short-term decline in preclinical Alzheimer disease. Neurology 2014;82:1760-7.
[45] Fagan T, Strobel G. https://www.alzforum.org/news/conferencecoverage/ban2401-removes-brain-amyloid-possibly-slows-cognitivedecline. Accessed February 20, 2019.

[46] https://www.lifetable.de/cgi-bin/data.php. Accessed October 1, 2018.

[47] Brookmeyer R, Abdalla N. Estimation of lifetime risks of Alzheimer's disease dementia using biomarkers for preclinical disease. Alzheimers Dement 2018;14:981-8.

\section{Did you know?}

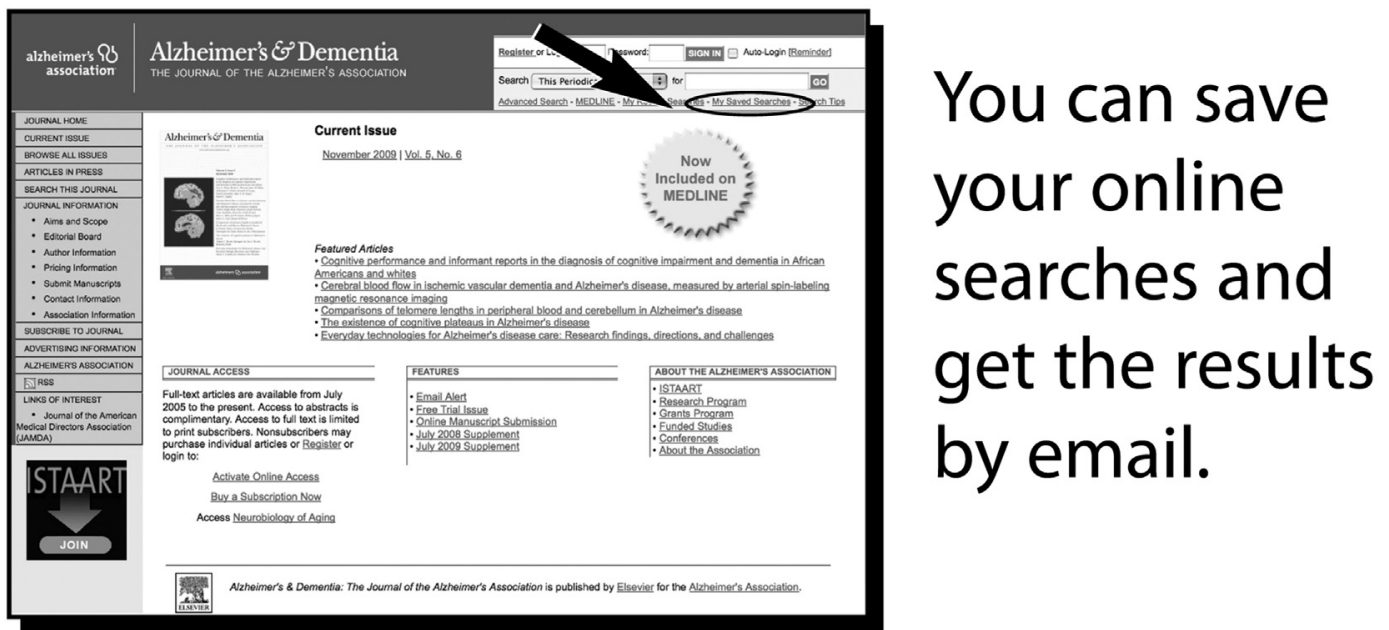

Visit www.alzheimersanddementia.org today! 